\title{
Research on incremental load power bicycle exercise on bone mineral density in patients with osteoporosis
}

\author{
Fangtao Liu, Qiaozhen Yan \\ School of Physical Education, Wenshan University, Wenshan 663099, China; \\ 112424@qq.com
}

Keywords: Incremental power, cycling, osteoporosis, bone mineral density

\begin{abstract}
Objective to explore the effect of incremental cycle ergometer exercise on bone mineral density in patients with osteoporosis. Methods 60 cases with osteoporosis in 2013 January-2014 year in January in our hospital as the research object, according to the different treatment as control group and observation group, the control group was given conventional bicycle exercise therapy, the observation group incremental cycle ergometer exercise therapy, compared two groups of bone mineral density and bone metabolism in patients with the situation. Results in the observation group after treatment, L1-L4 BMD $(1.23+0.03) \mathrm{g} / \mathrm{cm} 2$, left femoral neck BMD $(1.01+0.02) \mathrm{g} / \mathrm{cm} 2$, significantly better than the control group $(1.13+0.01) \mathrm{g} / \mathrm{cm} 2,(0.94+0.01) \mathrm{g} / \mathrm{cm} 2$, the difference was statistically significant $P<0.01$. The observation group after treatment of hip bone mineral density is $(0.70+0.17) \mathrm{g} / \mathrm{cm} 2$, the bone density of the lumbar spine is $(0.95+0.28) \mathrm{g} / \mathrm{cm} 2$, significantly better than the control group $(0.62+0.12) \mathrm{g} / \mathrm{cm} 2,(0.84+0.10) \mathrm{g} / \mathrm{cm} 2$, the difference was statistically significant $\mathrm{P}<0.05$. Conclusion the clinical effect of incremental cycle ergometer exercise in treating senile osteoporosis significantly, can effectively promote the bone mineral density and bone absorption of patients, has good effect on prevention of patients with fracture.
\end{abstract}

\section{Introduction}

As the global population continues to accelerate aging, the incidence of senile osteoporosis will rise 3-4 times ${ }^{[1]}$.In recent years, clinical osteoporosis prevention mainly through improving the patient's bone density as the focus, while the calcium and vitamin $\mathrm{D}$ as a supplement to base ${ }^{[2]}$.A lot of basic research and clinical practice has proved that the motion for osteoporosis treatment has an important role in the composition and the appropriate amount of exercise can improve the biomechanical properties of bone, increase bone density while improving bone metabolism ${ }^{[3]}$. Our hospital to explore the impact of different power cycling on bone mineral density in patients with osteoporosis, 30 patients underwent an incremental load cycle ergometer, the results are summarized as follows.

\section{Materials and Methods}

General Information. The January 2013-January 2014 Wenshan City First People's Hospital treated 60 cases of bone surgery osteoporosis patients for the study, according to different treatment modalities were divided into control group and observation group,30 cases. Control group, 14 males and 16 females; aged 63-78 years, mean age (68.4 \pm 3.7$)$ years; weight 56-72kg,average (62.3 \pm 4.1$)$ $\mathrm{kg}$. Observation group 15 males and 15 females; aged 61-79 years, mean age (68.0 \pm 3.9$)$ years;

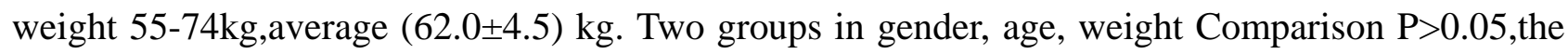
difference was not statistically significant. Inclusion criteria:(1)post-menopausal women aged 50 
years and over one year for men over age 65;(2) by DXAs diagnosed osteoporosis patients;(3)were treated conservatively(4)and with the informed consent of the respondents survey. Exclusion criteria:(1)not diagnosed with osteoporosis;(2) confusion, mental retardation;(3)various reasons cannot interfere with the completion of those; (4)persons with serious medical illness;(5)secondary osteoporosis; (6) cancer, tuberculosis. Diagnostic criteria for osteoporosis ${ }^{[4]}$ :World Health Organization to develop a bone density measurement-based diagnostic criteria for osteoporosis, as our reference. Normal: BMD (bone mineral density) values lower than normal bone density in young adults within one standard deviation of the (T higher than -1). Bone loss: BMD values lower than normal bone density in young adults between 1 and 2.5 standard deviations ( $\mathrm{T}$ values between-1 and -2.5).Osteoporosis: BMD value less than or equal to 2.5 standard deviations of normal young men ( $\mathrm{T}$ equal to the value of less than-2.5). Had one or more fractures are certainly experiencing severe or diagnosed osteoporosis.

\section{Test Method}

Starting load: woman/man, 80 W/100 W. 1.2.2 Increasing load: 3 min increments Act (Act 3 min): Women/Men were 3 min increments $40 \mathrm{~W} / 50 \mathrm{~W}$ to exhaustion; 1 min increments Act (Act $1 \mathrm{~min}$ ): Women / Men were $1 \mathrm{~min}$ increments 20W/25W to exhaustion; linear incremental method (linear method): $30 \mathrm{~s}$ increments $10 \mathrm{~W}$ to exhaustion; two groups of patients were bicycle speed control system at $60 \mathrm{~m} / \mathrm{min}$.(Exhaustive criteria: 1) when the intensity reaches a certain, $\mathrm{VO}_{2}$ max increased heart rate and no longer appear platform; 2) respiratory quotient $>1$ 10, HR more than 180 times/min, Lac $>7 \mathrm{mmol} / \mathrm{L}$; 3). achieve physical exhaustion, the subject can maintain the original velocity. )

Outcome Measures. Two groups were compared before and after experimental bone density changes, while at the end of the experiment on bone metabolism in two groups of patients were recorded, including indexes of bone formation (BGP) and bone resorption index (U-Pyd /Cr).

The statistical analysis. The study used SPSS18.0 statistical software for data processing, in which the count data $n(\%)$ that the use of $\chi^{2}$ test; measurement data $\left(\chi^{ \pm} \mathrm{s}\right)$ said, using test, the results of $\quad \mathrm{P}<0.05$ representing the difference between statistically significant.

\section{Result}

Before and after treatment changes in BMD: Observation group after treatment BMD L1-L4 was $(1.23 \pm 0.03) \mathrm{g} / \mathrm{cm}^{2}$, the left femoral neck BMD was $(1.01 \pm 0.02) \mathrm{g} / \mathrm{cm}^{2}$, significantly better than the control group $(1.13 \pm 0.01) \mathrm{g} / \mathrm{cm}^{2},(0.94 \pm 0.01) \mathrm{g} / \mathrm{cm}^{2}$, the difference was statistically significant $\mathrm{P}<0.01$. Table 1 . 
Table 1 in the two groups before and after treatment BMD changes $\left(\chi+\mathrm{s}, \mathrm{g} / \mathrm{cm}^{2}, \mathrm{ug} / \mathrm{l}, \mathrm{nmol} / \mathrm{mmol}\right)$

\begin{tabular}{cccccc}
\hline & & \multicolumn{2}{c}{ L1-L4 } & L1-L4 & \multicolumn{2}{c}{ On the left side of the femoral neck } \\
\cline { 3 - 6 } group & cases & $\begin{array}{c}\text { Before } \\
\text { the treatment }\end{array}$ & $\begin{array}{c}\text { After } \\
\text { treatment }\end{array}$ & Before the treatment & After treatment \\
\hline The control group & 30 & $1.06 \pm 0.01$ & $1.13 \pm 0.01$ & $0.86 \pm 0.01$ & $0.94 \pm 0.01$ \\
& & & $1.23 \pm 0.03^{*}$ & $0.86 \pm 0.01$ & $1.01 \pm 0.02^{*}$ \\
Observation group & 30 & $1.06 \pm 0.01$ & $*$ & 0.000 & 17.146 \\
T value & & 0.000 & 17.320 & 1.000 & 0.000 \\
P values & & 1.000 & 0.000 & $3.19 \pm 0.15$ & $8.07 \pm 0.74$ \\
BGP & & $4.78 \pm 0.78$ & $9.15 \pm 0.38$ & $6.17 \pm 0.52$ & $3.61 \pm 0.16^{*}$ \\
U-Pyd/Cr & $5.21 \pm 0.93$ & $3.23 \pm 0.3^{* *}$ & & \\
\hline
\end{tabular}

Note: * compared with the observation group, $\mathrm{P}<0.05$. ** With the observation group, $\mathrm{P}<0.01$.

\section{Changes in bone mineral density before and after treatment in two groups compared in Table}

2. Observation group after treatment, bone mineral density in the hip was $(0.70 \pm 0.17) \mathrm{g} / \mathrm{cm}^{2}$, lumbar spine bone mineral density was $(0.95 \pm 0.28) \mathrm{g} / \mathrm{cm}^{2}$, significantly better than the control group $(0.62 \pm 0.12) \mathrm{g} / \mathrm{cm} 2,(0.84 \pm 0.10) \mathrm{g} / \mathrm{cm}^{2}$, the difference was statistically significant $\mathrm{P}<0.05$.

Table 2 changes of the two groups before and after treatment in patients with bone density comparison $\left(\chi+\mathrm{s}, \mathrm{g} / \mathrm{cm}^{2}, \mathrm{ug} / \mathrm{l}, \mathrm{nmol} / \mathrm{mmol}\right)$

\begin{tabular}{ccllll}
\hline \multirow{2}{*}{ grouping } & cases & \multicolumn{3}{c}{ The hips } & \multicolumn{2}{c}{ Lumbar is a } \\
\cline { 3 - 6 } & & Before the treatment & After treatment & Before the treatment & After treatment \\
\hline The control group & 30 & $0.61 \pm 0.11$ & $0.62 \pm 0.12$ & $0.78 \pm 0.13$ & $0.84 \pm 0.10$ \\
Observation group & 30 & $0.61 \pm 0.10^{*}$ & $0.70 \pm 0.17^{*}$ & $0.80 \pm 0.11^{* *}$ & $0.95 \pm 0.28^{*}$ \\
T value & - & 0.000 & 2.105 & 0.643 & 2.026 \\
P values & - & 1.000 & 0.039 & 0.522 & 0.047 \\
BGP & - & $6.04 \pm 1.28$ & $14.65 \pm 2.57^{*}$ & $6.78 \pm 1.02$ & $15.07 \pm 3.61^{*}$ \\
U-Pyd/Cr & - & $6.04 \pm 1.30$ & $4.04 \pm 0.91^{* *}$ & $5.56 \pm 2.21$ & $2.36 \pm 1.50^{* *}$ \\
\hline
\end{tabular}

Note: * compared with the observation group, $\mathrm{P}<0.05$. ** With the observation group, $\mathrm{P}<0.01$.

\section{Discussion}

We want to ensure bone health, through movement, not only can improve the biomechanical properties of bone, bone density, and can improve the patient's bone formation and resorption. The effects of different exercise periods are different ${ }^{[5]}$, childhood exercise can increase bone mass in adulthood and sports will receive a bone and its preservation, elderly exercise is able to save and effective in preventing bone mass loss of its. So that different movement, on patients with bone mineral density caused by different intensities and frequencies are different, the prevention and treatment of osteoporosis process should be combined with the actual situation of patients ${ }^{[6]}$. The main determinant of bone strength including bone density, bone mineral density testing and diagnosis of osteoporosis is the gold standard, but also to predict the probability of patients with fractures for osteoporosis treatment effect will be to provide effective parameters. Related research indicates $^{[7]}$, by increasing peak bone mass can delay and reduce the loss of bone mass.

When motion is usually carried out at the standard time and frequency on no uniform, generally patients feel no fatigue tolerance to ${ }^{[8]}$. Through appropriate intensity aerobic exercise can effectively 
improve the patient's bone density at the same time within a certain range, the longer the time of patient motion, the higher the frequency the greater the stimulation of bone stress can effectively maintain and improve the content of bone mineral density. But each exercise time not too long, and the frequency can not be too large, or have a negative effect. If you want to improve bone density must let the patient movement lasted more than three months, once the stop motion in patients with bone minerals can significantly reduce, or even lower than the original level, so exercise to increase bone mineral density the effect is reversible, but the movement must persevere ${ }^{[9-10]}$. The study found that exercise can increase the power of the patient's bone mineral density by increasing the load to some extent the formation of bone metabolism $(\mathrm{P}<0.05)$, the observation group after treatment of L1-L4 BMD was $(1.23 \pm 0.03) \mathrm{g} / \mathrm{cm}^{2}$, the left femoral neck BMD was $(1.0 \pm 0.02) \mathrm{g} / \mathrm{cm}^{2}$, significantly better than the control group $(1.13 \pm 0.01) \mathrm{g} / \mathrm{cm}^{2},(0.94 \pm 0.01) \mathrm{g} / \mathrm{cm}^{2}$, the difference was statistically significant $\mathrm{P}<0.01$. Observation group after treatment, bone mineral density in the hip was $(0.70 \pm 0.17) \mathrm{g} / \mathrm{cm}^{2}$, lumbar spine bone mineral density was $(0.95 \pm 0.28) \mathrm{g} / \mathrm{cm}^{2}$, significantly better than the control group $(0.62 \pm 0.12) \mathrm{g} / \mathrm{cm}^{2},(0.84 \pm 0.10) \mathrm{g} / \mathrm{cm}^{2}$, a statistically significant difference.

In summary, the incremental load cycle ergometer senile osteoporosis significant clinical effect, can effectively promote the patient's bone mineral density and bone resorption, prevention of fractures in patients with good effect.

\section{References}

[1] Y.M. Wu,X.B. Hao,etc. Chinese journal of gerontology, 2014,23(14):4113-4115.

[2] R.R. show, Yuliu jian.Chinese journal of gerontology,2014,8(23):6736-6737.

[3] Q. S., J.Y. Yu, Korea, etc. Chinese journal of nursing, 2013, 48(4):331-334.

[4] L. G. ,H. X., J. Z. etc. Chinese journal of osteoporosis, 2014, 12(8):948-951.

[5] X. C.,H. A.,T.Y. Hu etc. The influence of basic medicine and clinical,2014，34(6):792-796.

[6] Hoegh A,Lindholt JS. Basic science review. Vasc Endovascular Surg, 2009,43(4):333-338.

[7] ShinguY,Shiiya N,Ooka T,et al. Ann Thorac Surg,2009,87(5):1373-1377.

[8] Várady E,Feher E,Levai A,et al. Clin Hemorheol Microcirc,2010,44(4):297-301.

[9] Araki T,Emoto M,Yokoyama H,et al. Metabolism,2011,55(5):587-592.

[10] Brodszki J,Lnne T,Marsál K,et al. Circulation,2011,111(20):2623-2628. 